\title{
Investigation of the parameters of the process of obtaining low-sulfur coke from heavy oil residues in the presence of a recycling agent
}

\author{
Nurdaulet Buzayev ${ }^{1 *}$, YermekAubakirov ${ }^{1}$, Firuza Akhmetova ${ }^{2}$, Manshuk Ibrayeva $^{3}$, Shynar \\ Sanyazova $^{3}$, Zhazira Mukazhanova ${ }^{3}$ \\ ${ }^{1}$ Al-Farabi Kazakh National University, Almaty, Kazakhstan \\ ${ }^{2}$ Zhangir khan West Kazakhstan Agrarian Technical University, 51 Zhangirkhan, Uralsk, Kazakhstan \\ ${ }^{3}$ Sarsen Amanzholov East Kazakhstan University, city 30 Gvardeiskoi divisii 34, Ust-Kamenogorsk, \\ Kazakhstan
}

\begin{abstract}
The current state of the oil refining industry is characterized by obtaining high-quality products that meet environmental requirements. An important issue is the deep processing of oil, as well as the use of oil waste as raw materials. In this regard, there is an interest in putting oil raw materials into operation through destructive processes: catalytic cracking, thermal cracking, visbreaking, coking, and processing of most of the oil waste. The article shows the possibility of producing coke with a low sulfur content from heavy oil waste from a domestic oil field. The physical and chemical properties of the extracted distillates are determined by chromatographic analysis and determined that the group-hydrocarbon composition corresponds to the composition of fractions obtained from primary atmospheric distillation. The process of obtaining of low-sulfur coke used as a conductor and oxidizer of electric current and raw materials in the production of structural material in the presence of a recycling agent from heavy oil waste from the Kumkol field was studied.
\end{abstract}

\section{Introduction}

Liquid fuel is used as fuel for a steam boiler. With heavy coking oil residues, highmolecular hydrocarbons and compounds decompose and a compaction reaction occurs, leading to the formation of coke. Coke from heavy oil waste is a promising raw material for the production of aluminum.

The production of petroleum coke in the refineries is progressively peaking up because of the trend of processing heavy crudes and in turn, a renewed interest in delayed coking process. Therefore, an efficient, economical, and environmentally safe utilisation of petroleum coke has become imperative in the current petroleum refining scenario[1].

Currently, for the process of coking heavy oil waste, the residual oil of the car engine is used as a recycling agent. The content of sulfates in the recycling agent, along with a decrease in the quality of the coke, reduces the plant's performance.

*Corresponding author: buzayev.n@gmail.com 
Delayed coking involves the thermal decomposition of oil residues (residues) to produce gas, liquid fractions, and coke. Slow coking of low-calorie residues from an increasing number of heavy and heavy-sulfur (high-sulfur) crude oils is carried out mainly by recycling these low-value residues by converting part of the residues into more valuable liquid and gaseous products and leaving a solid residue of the coke product. Although the resulting coke product is usually regarded as a low-value by-product. It may have some value, depending on its grade, as a fuel (fuel coke), electrodes for the production of aluminum (anode coke), and so on.in Addition, the economic value can be compensated if the morphology of the resulting coke is controlled to increase the productivity of the process, for example, by forming loose crushed coke[2].

Thermal cracking processes, such as visbreaking, and coking, without requiring expensive catalysts, are still attractive methods for heavy oil upgrading from an economic viewpoint [3]. The composition of petroleum coke also varies with the source of the crude oil, but in general, large amounts of high-molecular-weight complex hydrocarbons, which are rich in carbon but correspondingly poor in hydrogen, make up a high proportion of the coke [4]. Reaction temperature significantly affects coke composition [5-8]. Coke formed at low temperatures is generally non polyaromatic in nature, whereas at temperatures above $350{ }^{\circ} \mathrm{C}$, the retained coke compounds become more carbonaceous and heavier, ultimately dominated by polyaromatics $[5,6]$.

Regarding coke morphology and composition, a higher deactivation is usually attained with an increasing amount of amorphous and encapsulating coke [9]. The carbon gasification may initiate from the surface of nonporous grains and then extended to the pore surface within the solid [10]. The characteristics and kinetics for gasification of the carbonaceous fuels, like, coal, biomass and their chars, have been extensively studied [11$14]$ also with various gas-solid reaction models.

The use of plastic waste as a coking material is warranted as long as it does not affect the desired quality characteristics of coke such as the Drum Index, Coke Strength after Reaction and Coke Reactivity Index [15]. Besides plastic, they also added light and heavy oil produced during the maintenance process of a steel plant. It was observed that both oils reduced the initial softening temperatures for plastic and coal to $125{ }^{\circ} \mathrm{C}$ and $398{ }^{\circ} \mathrm{C}$, respectively. Moreover, the addition of plastic or oil had little influence on final coke quality, with respect to the parameters assessed [16]. The use of these wastes in coking can be a good option, which may also indirectly reduce the operating cost of Brazilian steel plants. This study aimed to assess the effects of adding plastics and waste cooking oil on coke quality in pilot coking ovens [15].

\section{Materials and methods}

\subsection{Equipment and procedure}

To conduct the coking process, the raw material is first placed in the reactor. $12 \mathrm{~g}$ of tar and $8 \mathrm{~g}$ of residual oil were used as raw materials. After loading the raw material inside the reactor, the reactor lid is closed with special bolts. To conduct the coking process in an inert environment, nitrogen gas is blown inside the reactor. After creating an inert medium in the reactor, the reactor pressure is adjusted to $0.4 \mathrm{MPa}$. After making sure that the system is tight, the process begins.

The furnace is heated using a laboratory autotransformer with the necessary current. A valve is used to regulate the pressure of $0.4 \mathrm{MPa}$. If the pressure exceeds $0.4 \mathrm{MPa}$, the valve outputs the excess pressure. The temperature transmitted to the system increases due to the 
current of the laboratory auto-transformer and is determined by thermocouples. Adds the time when the system temperature reaches $365^{\circ} \mathrm{C} .3$ hours after reaching this temperature, all the pressure in the system is removed and the process is carried out for another 1 hour under the process pressure. The temperature is in the range of $490-510^{\circ} \mathrm{C}$.

Condense the released vapors during the coking process using the reverse refrigerator, into the receiving flask of liquid products. The extracted gas is collected on the gasometer.

After complete completion of the process, the furnaces, laboratory auto-transformer, and refrigerators are turned off and the coke contents are cleaned after the reactor is cooled.

\subsection{Analytical methods}

During the coking process, the extracted distillates are separated into fractions by atmospheric distillation. Products obtained by pumping are sent for chromatographic analysis. The resulting liquid products were examined on an Agilent $6890 \mathrm{~N}$ gas chromatograph with a flame-ion detector. This chromatograph allows you to identify unknown compounds and get the results of highly selective gas chromatographic analysis. Liquid coking products are analysed using the Kovac index. HP-1.60m-0.32 mm-25 nitrogen gas was used in the analysis process.

One of the methods of electron microscopy, the morphology of samples synthesized as a result of the SIS process using scanning electron microscopy (SEM), was studied in the raster electron microscope of the NNLOT DGP-Quanta 3D 200i Dual system, FEI.

Determination of the sulfur content in the starting substances and starting products was carried out using the SPECTROSCAN S. x-Ray energy dispersion SPECTROSCAN analyzer $\mathrm{S}$ is designed to determine the mass fraction of sulfur in oil and petroleum products. The analysis is performed when the chemical elements are excited for 10-100 minutes after the sample is placed in a special cell.

One of the methods of spectroscopy was to study the group-chemical composition of the product formed as a result of the process using Raman spectroscopy. For this purpose, the Raman spectroscopy apparatus Labram HR 800 DGP "NNLOT" was used, located at the faculty of physical engineering of the Kazakh national University.al-Farabi.

Raman spectra are very sensitive to the nature of chemical bonds in organic molecules and polymer materials, inorganic crystal lattices, and clusters.

\section{Results and discussion}

The results of chromatographic analysis of fractions of gasoline, light gas oil, and heavy gas oil by atmospheric distillation of distillates obtained by coking heavy oil waste in the presence of a recycling agent can be seen in Table 1.

This table illustrates that aromatic hydrocarbon and alkane content in liquid fractions are dominated. A heavy oil residue is the main source of the formation of a large number of saturated compounds in liquid fractions. The aroma of liquid fractions can be due to the content of aromatic compounds in the heavy oil residue. Moreover, the Diels - Alder reaction (the formation of aromatic heterocycles from alkenes) may be one of the reasons for the aromaticity of liquid products 
Table 1.Chemical composition of distillates obtained by coking heavy oil waste in the presence of a recycling agent.

\begin{tabular}{|c|c|c|c|}
\hline $\begin{array}{c}\text { Group chemical } \\
\text { composition } \\
\text { of hydrocarbons }\end{array}$ & $\begin{array}{c}\text { Gasolinefraction,0- } \\
180^{\circ} \mathrm{C}\end{array}$ & $\begin{array}{c}\text { Light gas oilfraction, } \\
180-240{ }^{\circ} \mathrm{C}\end{array}$ & $\begin{array}{c}\text { Heavy gas oilfraction, } \\
240-320^{\circ} \mathrm{C}\end{array}$ \\
\hline Alkanes & 15.53 & 17.82 & 19.14 \\
\hline Isoalkanes & 3.57 & 1.36 & 0.98 \\
\hline Alkers & 7.44 & 2.56 & 4.53 \\
\hline Cycloalkane & 2.19 & 2.25 & 1.24 \\
\hline Aromatichydrocarbon & 25.83 & 9.84 & 11.35 \\
\hline
\end{tabular}

Raman spectroscopy was used to determine the group composition of coke obtained during coking. The structure of the coke produced during the process is shown in Table 2 and Figure 1.

Table 2.Structure of coke produced in the presence of a recycling agent.

\begin{tabular}{|c|c|}
\hline $\begin{array}{c}\text { Values of } \\
\text { peak frequency, } \mathrm{cm}^{-1}\end{array}$ & Peak description \\
\hline $1185-1230$ & C-C bond, aromatic compounds \\
\hline $1230-1345$ & Alkyl ether of aryl \\
\hline $1345-1385$ & High-quality carbon materials \\
\hline $1385-1465$ & Methyl group, aromatic bond \\
\hline $1465-1540$ & Amorphous carbon construction \\
\hline $1540-1595$ & Graphitic \\
\hline $1595-1700$ & Methods for the determination of carbonyl groups \\
\hline
\end{tabular}

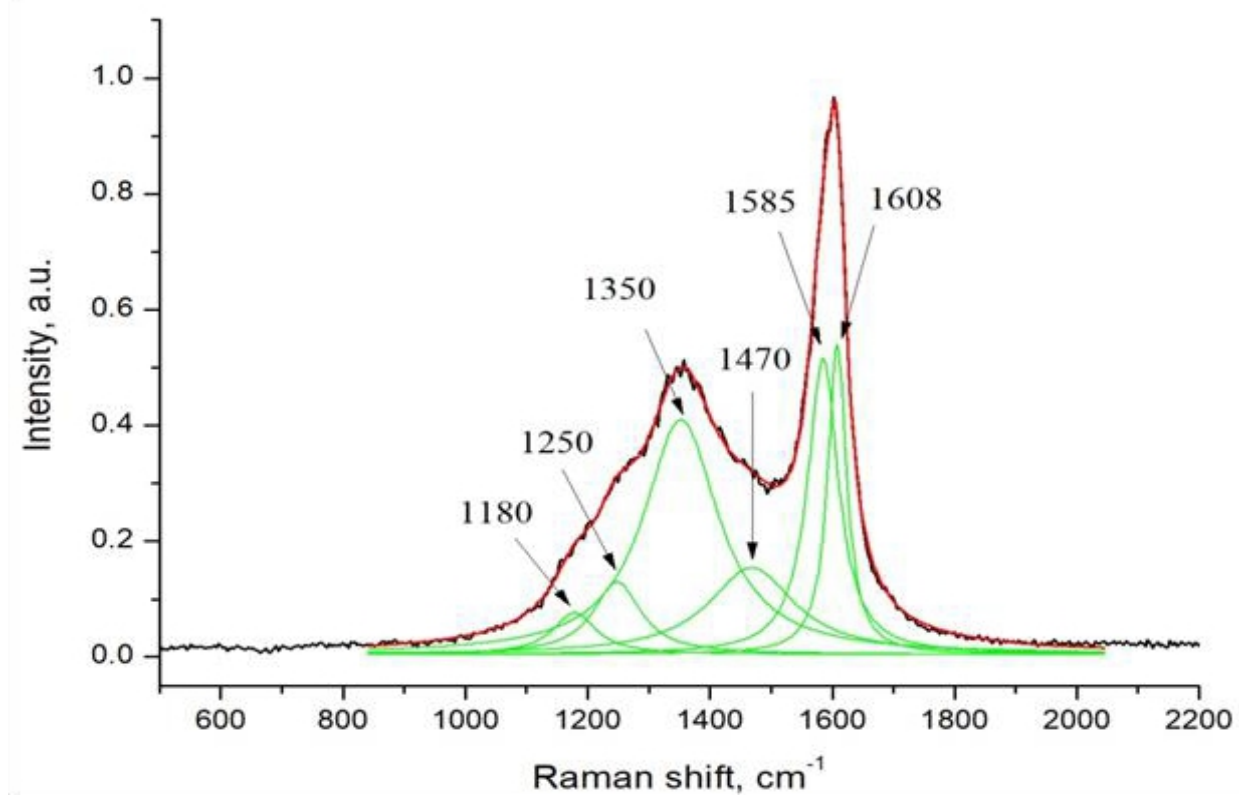

Fig.1. Raman spectrum of coke.

The composition of coke includes a large number of chemical compounds. It known that the cyclic and aromatic bonds affect the large formation of coke. The presence of 
graphite increases the rigidity of the coke. Chemical bonds and compounds have a great influence on the structure of coke.

To determine the microstructure of coke obtained as a result of coking, an image was Scanned for electron microscopy. Figures 2 and 3 shows images of microstructures of various sizes of coke obtained in the presence and without the participation of a recycling agent.

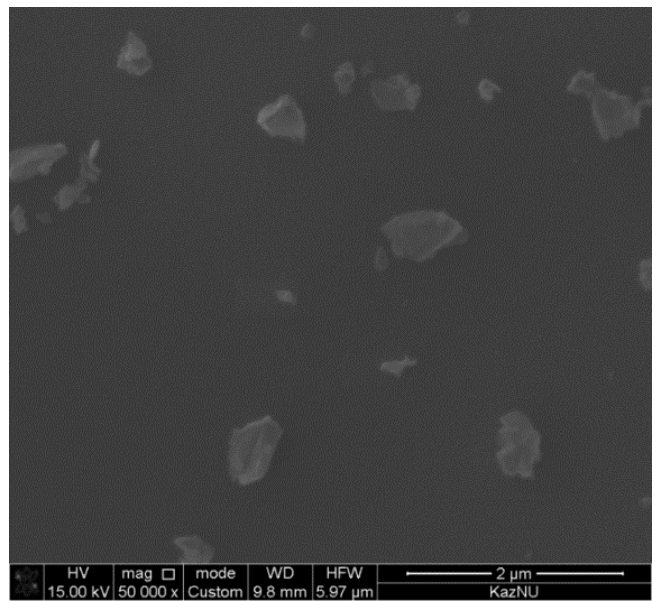

a

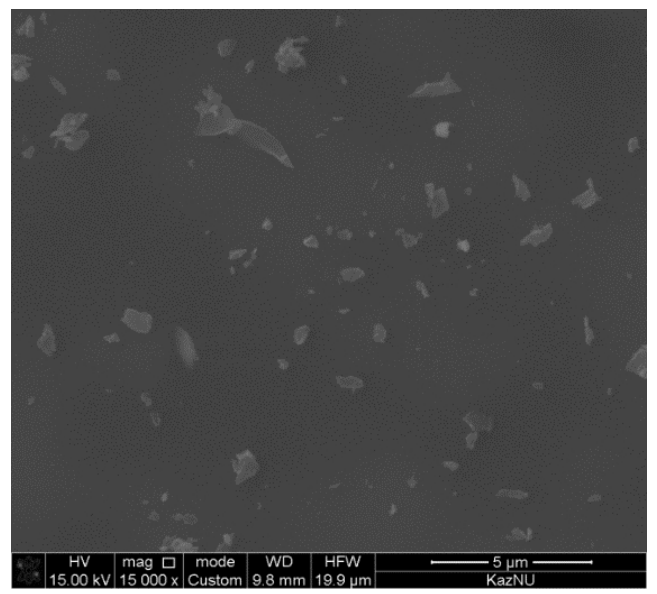

c

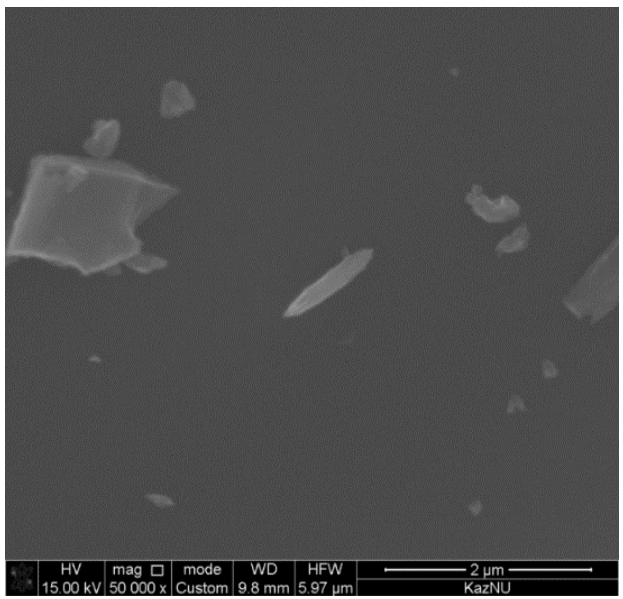

b

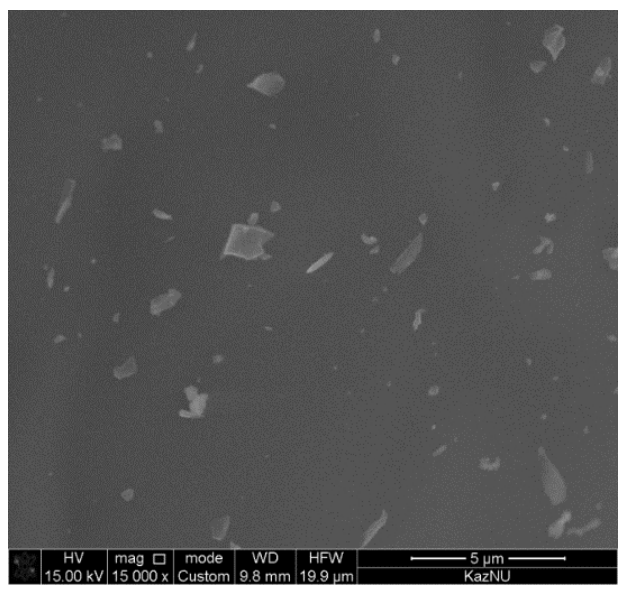

d

Fig. 2. SEM micrographs of coke obtained:

a) $\times 50000$ without recycling agent; b) x 50000 in the presence of recycling agent;

c) $\mathrm{x} 15000$ without recycling agent; d) x 15000 in the presence of recycling agent.

The composition of coke includes a large number of chemical compounds. The presence of graphite increases the rigidity of the coke. Chemical bonds and compounds have a great influence on the structure of coke.

The sulfur content of the resulting coke reduced by thermal dehydration. Increasing the temperature and increasing the pressure causes to the reducing of sulfur content to more than $2.5 \%$ and the quality of the coke become well. It turned out that with the addition of a recycling agent, yield of coke from heavy oil waste is increased.

The sulfur content of coke and liquid products when coking heavy oil waste in the presence of a recycling agent is indicated in Table 3 . 
Table 3. The content of sulfur in products formed during coking, mass. \%

\begin{tabular}{|c|c|c|c|c|}
\hline Components & Gasoline & Light gas oil & Heavy gas oil & Coke \\
\hline $\begin{array}{c}\text { Sulfur } \\
\text { content }\end{array}$ & 0.132 & 0.802 & 0.432 & 0.930 \\
\hline
\end{tabular}

In Table 4 the material balance is shown for the process of obtaining low-sulfur coke in the presence of a recirculating agent.

Table 4. Material balance of the process

\begin{tabular}{|l|c|c|l|c|c|}
\hline Input & $\mathrm{m}, \mathrm{g}$ & mass. \% & Output & $\mathrm{m}, \mathrm{g}$ & mass. \% \\
\hline Tar & 10 & 50 & Coke & 4.53 & 22.65 \\
Residue oil & 10 & 50 & Distillates & 14.00 & 70.00 \\
& & & Gas & 1.00 & 5.00 \\
& & & Loss & 0.47 & 2.35 \\
\hline Overall & 20 & 100 & Overall & 20 & 100 \\
\hline
\end{tabular}

\section{Conclusion}

In the presence of a heavy oil residue and a recycling agent, we obtained a low sulfur coke. The yield of coke and liquid distillates is $22.65 \%$ and $70 \%$, respectively. The physicochemical properties of the obtained liquid products discovered and it proved that in composition they correspond to the distillates obtained by atmospheric distillation. The ash content of the coke obtained by processing the reagent is $0.320 \mathrm{wt} . \%$. The structure of the formed cokes and the microstructure of various scales revealed. Coking of heavy oil residues in the presence of a recirculating agent is a cost-effective way to obtain liquid products and coke for industrial targets.

\section{References}

1. H.Q. Liao, G.W. Yu, P. Zhao, Y.B. He, J.J. Cai, B.Q. Li,New process of co-coking of waste plastics and blend coal Coke Oven Managers,6(2006)

2. Y. Zhang, L. Huang, X. Xi, W. Li, G. Sun, S. Gao, S. Zhang, EF, 31, 8 (2017)

3. J.G.Speight, 19(2015)

4. ZhijianWan, Gang KevinLi, ChuanfuWang, HongYang, DongkeZhang, Appl. Cat. A, 549, 11(2018)

5. M. Guisnet, P. Magnoux, Appl. Cat. A,212, 14 (2001)

6. M. Guisnet, L. Costa, F.R. Ribeiro, J. Mol. Cat. A,305, 15(2009)

7. S. Muller, Y. Liu, M. Vishnuvarthan, X.Y. Sun, A.C. van Veen, G.L. Haller, M. Sanchez, J.A. Lercher, J Cata.,325,12 (2015)

8. A. Ochoa, J. Bilbao, A.G.Gayubo, P. Castano, RSER, (2019)

9. M. Siskin, S. R. Kelemen, M. L. Gorbaty, D. T. Ferrug, E \& F, 20, 8 (2006)

10. Y.Zhang, M.Yao, S.Gao,G.Sun, G.Xu, Appl. E, 160, 9 (2015)

11. A.Gomez, N.Mahinpey, Appl. E, 1, 33 (2015)

12. L.Zhang, J.Huang, Y.Fang, Y.Wang, EF, 3, 10(2006)

13. I.I.Ahmed, A.K.Gupta, Appl. E, 5, 9(2011)

14. L.Ren, J.Yang, F.Gao, J.Yan, EF, 9, 10(2013)

15. L.C. Lange, A.F.M. Ferreira,WM 61, 7 (2017)

16. K. Kato, S. Namura, H. Uematsu, ISIJ Int., 42, 4(2002) 